\title{
O DESENVOLVIMENTO DA FILOGÊNESE E DA ONTOGÊNESE DA LINGUAGEM: ALGUNS ASPECTOS, SEGUNDO A TEORIA HISTÓRICO- CULTURAL
}

\author{
Cleber Barbosa da Silva CLARINDO ${ }^{1}$ \\ Thaís BORELLA ${ }^{2}$ \\ Rosane Michelli de CASTRO ${ }^{3}$
}

RESUMO: Apresentam-se, neste artigo, resultados de parte dos estudos voltados para análise e interpretação de aspectos relativos ao desenvolvimento da filogênese e da ontogênese da linguagem. Tais estudos foram realizados em cursos de formação de professores e em grupos de pesquisas que centram suas discussões em aspectos segundo a perspectiva da Teoria Histórico-Cultural, ou escola de Vygotsky e seus seguidores. Nesse sentido, todo o texto pauta-se na formulação de que o desenvolvimento e a apropriação da linguagem são processos histórico-culturais que decorrem da necessidade humana de comunicação e têm origem na atividade vital humana, ou seja, no trabalho socialmente constituído. Ao final, ressaltam-se, centralmente, as relações sociais e a sua importância tanto no desenvolvimento da linguagem quanto no desenvolvimento global do homem, além de considerar o desenvolvimento e a apropriação da linguagem como o ponto central do desenvolvimento humano. Para a realização dos estudos foram utilizados procedimentos da pesquisa bibliográfica, basicamente, de leitura, análise e, ainda que breve, de interpretação, à luz de bibliografia específica.

PALAVRAS-CHAVE: Educação. Formação de professores. Filogênese da linguagem. Ontogênese da linguagem. Teoria Histórico-Cultural.

\section{Introdução}

É possível afirmarmos que o convívio das pessoas em sociedade é responsável pelas constantes transformações (movimentos dialéticos) que ocorrem ao longo do processo de sua formação.

Muitos pesquisadores dedicaram-se e ou dedicam-se aos estudos sobre o desenvolvimento humano, dentre eles sobre o desenvolvimento da linguagem, cujo suporte é a história e o meio cultural em que a pessoa está inserida, os quais exercem influência decisiva sobre ela. Dentre tais pesquisadores, é possível destacarmos as

\footnotetext{
${ }^{1}$ Mestrando em Educação. UNESP - Universidade Estadual Paulista. Faculdade de Filosofia e Ciências Pós-Graduação em Educação. Marília - SP - Brasil. 17525-000 - cleber_clarindo@ hotmail.com.

2 Mestranda em Educação. UNESP - Universidade Estadual Paulista. Faculdade de Ciências e Tecnologia. Presidente Prudente - SP - Brasil. 19060-900 - thaisborella1 @ gmail.com.

3 Docente da Pós-Graduação em Educação. Universidade Estadual Paulista. Faculdade de Filosofia e Ciências. Marília - SP - Brasil. 17525-000 - rosanemichelli@ marilia.unesp.br.
} 
contribuições de Lev Semenovitch Vygotsky (1896-1934) e de alguns de seus seguidores como Alexander Romanovich (1902-1977) e Alexis Leontiev (1903-1979), cujas formulações possuem fundamento no conceito marxista do materialismo históricodialético.

O materialismo histórico-dialético descoberto por Marx ao estudar a sociedade capitalista, caracteriza-se por conceber o mundo dos homens como a síntese da prévia-ideação com a realidade material, típica e elementarmente por meio do trabalho. As dimensões ideal e material dos atos humanos são integradas, possibilitando tanto reconhecer a importância das idéias para a história, quanto a sua impotência quando não encontram as condições históricas necessárias para que sejam traduzidas em prática (para que sejam objetivadas) por atos humanos concretos. (LESSA; TONET, 2008, p.45).

Na abordagem vygotskyana, o homem é visto como alguém que transforma e é transformado nas relações que acontecem em uma determinada cultura. O que ocorre não é uma somatória entre fatores inatos e adquiridos e sim uma interação dialética que se dá, desde o nascimento, entre o ser humano e o meio social e cultural em que se insere. Assim é possível constatar que o ponto de vista de Vygotsky é que o desenvolvimento humano é compreendido não como decorrência de fatores isolados que amadurecem, nem tampouco de fatores ambientais que agem sobre o organismo controlando seu comportamento, mas sim como produto de trocas recíprocas que se estabelecem durante toda a vida, entre individuo e meio, cada aspecto influindo sobre o outro. (NEVES; DAMIANI, 2006, p.7).

Segundo Vygotsky (1993), em seu livro Pensamento e Linguagem, para se obter uma resposta concisa e lógica para o questionamento acerca do desenvolvimento da linguagem, é de fundamental importância que se utilize um método de pesquisa que aborde de forma global o sujeito, sem que sejam estudadas isoladamente suas funções cognitivas, sendo que para Vygotsky, não há como dissociar pensamento e palavra.

Para Vygotsky (1993, p.5) “A função primordial da fala é a comunicação, o intercâmbio social":

A verdadeira comunicação humana pressupõe uma atitude generalizante, que constitui um estágio avançado do desenvolvimento do significado da palavra. As formas mais elevadas da comunicação humana somente são possíveis porque o pensamento do homem reflete uma realidade conceitualizada. É por isso que certos pensamentos não podem ser comunicados às crianças, mesmo que elas estejam familiarizadas com as 
palavras necessárias. Pode ainda estar faltando o conceito adequadamente generalizado que, por si só, assegura o pleno entendimento. Em seu trabalho sobre educação, Tolstoi afirma que a dificuldade que as crianças frequentemente apresentam de aprender uma palavra nova é devida ao conceito a que a palavra se refere, e não ao seu som. Uma vez que o conceito esteja amadurecido, haverá quase sempre uma palavra disponível.

Segundo essa afirmação de Vygotsky (1993), fica evidente que é impossível considerarmos o homem como um ser que se desenvolve apenas biologicamente, sendo necessário compreendermos que a relação que o homem estabelece com o meio em que vive e as relações interpessoais influenciam e modificam seu desenvolvimento, de onde decorre a formulação de que o desenvolvimento e a apropriação da linguagem é um processo histórico-cultural que ocorre diante da necessidade humana de comunicação e origina-se da atividade vital humana, ou seja, o trabalho socialmente constituído.

Além das afirmações de Vygotsky (1993), também em Luria (1986) encontramos subsídios teóricos que respaldam a importância do convívio social do homem para o desenvolvimento da linguagem:

Para explicar as formas mais complexas de vida consciente do homem é imprescindível sair dos limites do organismo, buscar as origens desta vida consciente e do comportamento "categorial", não nas profundidades do cérebro ou da alma, mas sim nas condições externas da vida e, em primeiro lugar, da vida social, as formas históricosociais da existência do homem.

Do exposto, tem-se que, é na atividade humana fundamental, ou seja, o trabalho social, que se cria no homem à necessidade de se comunicar, assim a linguagem é um dos fatores decisivos para passagem da conduta instintiva animal do homem para a conduta consciente.

$\mathrm{Na}$ atividade do trabalho as ações são designadas, e nesse processo nasce à linguagem. De inicio toda relação da ação com a linguagem esta intimamente ligada com o caráter prático dessa ação. O sentido dos sons e gestos dependia das situações práticas realizadas.

O segundo fator decisivo que determina a passagem da conduta animal à atividade consciente do homem é a aparição da linguagem. No processo do trabalho socialmente dividido, surgiu nas pessoas à necessidade imprescindível de uma comunicação estreita, a designação da situação laboral na qual tornavam parte, ocasionando a aparição da linguagem. Nas primeiras etapas, esta linguagem esteve estreitamente ligada aos gestos, os sons inarticulados podiam significar tanto "cuidado" 
"como" "esforça-te", etc., ou seja, o significado do som dependia da situação prática, das ações, dos gestos e da entonação com que era pronunciado.

O nascimento da linguagem levou a que, progressivamente, fosse aparecendo todo um sistema de códigos que designava objetos e ações e suas relações. Finalmente, formaram-se códigos sintáticos complexos de frases inteiras, as quais podiam formular as formas complexas de alocução verbal. (LURIA, 1986, p.22).

O desenvolvimento da linguagem ao longo da história humana e a complexificação dos códigos é de fundamental importância no caráter consciente das relações humanas, possibilitando ao homem sair dos limites instintivos dos animais. Através desse contexto é necessário fazer uma análise concreta do papel da linguagem e suas especificidades que deram e dão a possibilidade do homem se constituir verdadeiramente em humano, ou seja, se apropriar da cultura humana construída historicamente, pois é na linguagem que se tem a origem da formação das categorias do mundo humano.

\section{O desenvolvimento da filogênese da linguagem}

Neste tópico, buscamos contemplar aspectos da filogênese da linguagem, ou seja, a história de como ocorre o desenvolvimento da linguagem no homem. Para tanto, iniciamos apresentando aspectos que afirmam a importância de reconhecermos o homem em sua totalidade, ou seja, não limitando o estudo do seu desenvolvimento à análise das suas particularidades capazes de minimizar e/ou reduzir essa estrutura complexa que é o gênero humano.

Sabemos que as ciências naturais e positivistas têm uma compreensão bastante objetiva e limitada aos aspectos biológicos e observáveis do ser humano, fato que garante certa compreensão da espécie humana, uma compreensão naturalizante. No entanto, quando se adentra ao campo das ciências humanas e sociais há que se ampliar à compreensão dos seres humanos e compreendê-los a partir de uma perspectiva mais ampla que considera a biologia, mas que não se limite a ela. Essa perspectiva é o que se denomina de dialética.

Definir o homem é muito difícil, pois seu grande potencial de transformação e criação, o faz se constituir de forma muito diversificada e complexa que não pode ser reduzida a particularidades estanques. 
Leontiev (2004) retrata bem essa ideia da complexidade humana quando em uma passagem do seu livro $O$ desenvolvimento do psiquismo afirma que, se por acaso um ser inteligente visitasse a terra e estudasse os seres humanos de varias regiões, dificilmente se admitiria tratar-se da mesma espécie, isso dada à grande diversidade de maneiras de ser, pensar e agir, além das grandes diferenças físicas entre os membros da espécie humana.

Assim, os seres humanos têm várias "faces", ou seja, são diferentes, não sendo possível uma análise simplista desses sujeitos, como são as análises feitas com os animais, que através da pesquisa de um único representante da espécie consegue-se definir o comportamento de todos ou da maioria dos membros de uma espécie.

No caso do homo sapiens, essa possibilidade não se configura como real, pois, cada indivíduo, ou melhor, dizendo cada grupamento social, possibilita determinados indivíduos e cada sociedade possibilita que os seres humanos tenham suas características de forma diferenciadas. Não estamos nos referindo às diferenças biológicas (genéticas) mais sim sociais, ou seja, cada sociedade tem seus traços culturais que a identifica e determina a partir das suas condições objetivas de vida. A vida dos seus indivíduos, que se diferenciam com suas características externas e internas, quer dizer, suas características objetivas (físicas) e subjetivas (pensamentos, sentimentos, consciência e a linguagem).

Com essa pequena introdução, podemos identificar que, na historia da humanidade esse sujeito diferenciado, o homem, se constituiu como um ser adiante de qualquer outro animal e diferenciou-se enormemente ao desenvolver capacidades únicas de transformar a natureza em seu benefício e não simplesmente adaptar-se a ela, refletir e planejar suas ações, ao invés de simplesmente responder a estímulos, agir conscientemente ao invés de ficar submetido ao ambiente, criar, pensar, desenvolver consciência e construir sua personalidade.

Mas como e porque o ser humano tem essa capacidade de diferenciar de qualquer outra espécie animal? Essa é a questão que não se esgota e as possíveis respostas serão encontradas a partir de uma profunda e radical análise sobre o processo de hominização que é a passagem da vida animal para a vida regrada pelas relações sociais intencionais, ou melhor, pela vida em sociedade que transcende qualquer outra forma de vida.

O homem tem sua origem na vida animal, sendo resultado da evolução, mas com a capacidade de transformar esse mundo de tal forma que se constitui nesse processo e 
superou sua condição primitiva e animal, distanciando-se dos demais animais presentes no planeta.

A hominização é organização física da espécie humana, ou seja, a passagem do animal para homem, constituído em suas aptidões legitimamente humanas através do seu desenvolvimento histórico e social a partir da construção de ferramentas fundamentais (materiais e simbólicas) essenciais para que o membro da espécie homo sapiens se tornasse um ser humano em processo de humanização.

Esta passagem do animal ao homem apresenta vários estágios, sendo o primeiro a preparação biológica humana, que tem como representantes os Australopitecos, que eram animais gregários, que já davam seus primeiros passos na posição vertical, além de utilizar objetos da natureza e iniciarem a produção de alguns instrumentos muito rudimentares e uma linguagem, ou melhor, dizendo um processo de comunicação bastante primitivo.

O segundo estágio desse desenvolvimento comporta a grande mudança rumo à humanidade. Esse estágio tem as características de possibilitar a formação real de uma sociedade e a consolidação do trabalho como atividade de transformação intencional da natureza para atender as necessidades do membro da espécie e do seu grupo. Iniciam-se a fabricação de instrumentos mais elaborados (por exemplo: uma lança), e a linguagem já ganha certo significado cultural; nesse estágio se encontra como principais representantes as seguintes espécies; o Pitecantropo e o homem de Neanderthal.

Nesse período, apesar de haver grandes transformações anatômicas, o desenvolvimento biológico já não mais determina a vida da espécie e sua ação na natureza, os membros da espécie, seus comportamento e maneiras de viver começam a ser regrados por novas leis, as leis da produção social, histórica e cultural.

No último estágio da hominização o homem liberta-se definitivamente das determinações biológicas e assume a sua ação intencional sobre a natureza e sobre os outros homens e junto aos objetos culturais com a possibilidade maior de desenvolvimento. Pode-se afirmar que toda grande evolução do homem tem agora como premissa as leis sócio-históricas, seu desenvolvimento passa a ser ilimitado e dependente somente das condições históricas e sociais e das possibilidades de apropriação dos objetos culturais.

A hominização se configura como a conquista da liberdade da espécie humana, que supera uma vida animal e de dependência das leis biológicas para atingir um estágio enorme na sua evolução como espécie. Essa liberdade só foi possível através da 
atividade do trabalho criativo em que os membros da espécie humana se dirigiram à natureza com intenção de transformá-la e ao realizarem esse primeiro ato histórico, tiveram criadas todas as condições para se constituírem como seres humanos, sujeitos da cultura.

O homem se deferência do animal pelo fato de que, com sua passagem à existência histórico-social, as formas de vida social a eles vinculados, muda radicalmente todas as categorias fundamentais do comportamento.

A atividade vital humana caracteriza-se pelo trabalho social e este, mediante a divisão de suas funções, origina novas formas de comportamento, independentes dos motivos biológicos elementares. A conduta já não está determinada por objetivos instintivos diretos. Desde um ponto de vista biológico, não há nenhum sentido em atirar sementes na terra em lugar de comê-las, em espantar a presa ao invés de capturá-la diretamente ou afiar uma pedra se não tem em conta que essas ações serão incluídas em uma atividade social complexa. $\mathrm{O}$ trabalho social e a divisão social do trabalho provocam aparição de motivos sociais de comportamento. (LURIA, 1986, p.21).

O homem transformou a natureza e, consequentemente, transformou a ele próprio. Isso foi possível pelo trabalho coletivo, pelo trabalho intencional, pois a espécie humana não mais se limitava a simplesmente submeter-se à natureza como os outros animais. Pode-se afirmar que a espécie humana ousou transformar a natureza para adaptá-la às necessidades dos membros do grupo. Certamente que não estamos a afirmar que, com a hominização, as leis biológicas têm um fim, sendo elas agora apenas uma estrutura para as leis que regem, verdadeiramente, o homem atual; mas estamos a afirmar que as leis biológicas não mais regem a vida dos indivíduos em sociedade. Elas garantem a manutenção do seu organismo vivo (físico e natural), mas todo o resto é garantido pela vida em sociedade e pela construção da cultura. Sem as leis iniciais biológicas e naturais não é possível a formação da superestrutura, ou seja, das condições sociais e históricas que fizeram do homem uma espécie única, transcendendo qualquer outra.

Então, a atividade transformadora e criadora que é o trabalho, essa ação essencialmente humana, é que deve ser valorizada no processo de evolução humana, pois, nesse processo o homem é sempre ativo e transformador, e a vida em sociedade é o que caracterizou a saída do homem da vida animal para ser verdadeiramente humano, ou seja, um ser social e histórico que o trabalho intencional constitui como homem humanizado. 
Mas, como se dá a atividade humana? E, o que diferencia a atividade humana de outras atividades de outras espécies? O que torna a atividade humana tão especial?

Teóricos afirmam que a evolução humana só foi possível na base da atividade fundamental humana que é o trabalho, o qual cria e recria as necessidades humanas, as quais só podem ser satisfeitas no seio do trabalho humano coletivo, pois não é possível conceber um homem isolado de seu grupo social.

O homem mediante a atividade do trabalho está em contato com a natureza e assim age sobre ela e, nessa ação, à medida que transforma a natureza, nem o homem nem a própria natureza continua a mesma; se transformaram numa dialética constante de tese, antítese e síntese, garantindo o movimento de transformação de ambos e, é importante salientar que nesse processo de transformação da natureza as necessidades humanas que a princípio eram naturais (fome de um indivíduo p. ex.) passam aos poucos a se tornarem sociais (saciar a fome do grupo p. ex) e, nesse processo é que se afirmam as leis sociais enquanto motor do desenvolvimento humano.

É importante esclarecer que, nesse processo, no momento em que as necessidades iniciais têm sua satisfação atendida, outras necessidades são criadas a partir dessa, se constituindo a relação dialética entre homem e natureza que se estrutura a partir da atividade do trabalho.

Todo o contexto que caracteriza o homem humanizado não se transmite pela a herança genética. Essas características humanas são desenvolvidas no seio das relações sociais da atividade do trabalho. Com base em tais ideias, Leontiev (2004) afirma que o olho humano vê coisas que nem a mais perspicaz ave de rapina enxerga; tem ouvidos que interpretam sons que nenhum outro animal com ouvidos muitos mais aguçados não conseguem. O desenvolvimento dessas funções dos órgãos da individualidade humana, desde o ouvido tonal ao pensamento verbal, se dá na atividade produtiva e coletiva humana.

Segundo o autor, o homem não nasce humano se forma homem e isso acontece com apropriação da cultura criada por muitas gerações, processo esse em que o homem se apropria dos fenômenos e dos objetos sociais e históricos, como produto da atividade realizada. Certamente que, para que esse processo aconteça, é importante que o sujeito tenha uma ação efetiva e intencional diante da natureza e/ou dos objetos culturais. Compartilhamos da crença de que o homem não se desenvolve espontânea e naturalmente, mas sim a partir de suas relações com a história e com os produtos 
culturais dessa história coletiva dos homens em sociedade na sua relação com a natureza.

Mas como esses traços se cristalizam nos objetos e se cria a cultura humana e como essa cultura se incorpora ao homem e ao seu mundo?

Diferentemente dos outros animais o homem possui a atividade do trabalho, trabalho esse como mencionado, apresenta-se como uma das principais ferramentas que possibilita a hominização; é no trabalho que a humanidade cria e transforma a natureza e se transforma também.

Devemos sublinhar que este processo sempre ativo do ponto de vista do homem. Para se apropriar dos objetos ou dos instrumentos ou dos fenômenos que são o produto do desenvolvimento histórico, é necessário desenvolver em relação a eles uma atividade que se reproduza, pela sua forma, os traços essenciais da atividade encarnada, acumulada no objeto. (LEONTIEV, 2004, p.286).

Essa possibilidade que os homens conquistaram pelo trabalho, ou seja, a atividade do significativo e intencional, planejado, transformou a espécie humana, possibilitando o atendimento das suas necessidades como espécie e, nesse processo, criando novas necessidades não mais naturais, mas sim construídas social e historicamente; criando assim bens culturais, do mais simples instrumento de pedra lascada para a atividade de caça, até o mais avançado computador que tem a potência de processar milhões de informações em milésimos segundos.

O poder de criação do trabalho faz o homem transformar não só a natureza como a ele mesmo, pois o desenvolvimento humano se dá no trabalho. Toda evolução da espécie seja intelectual ou nas aptidões motoras, sociais ou afetivas, como em outras esferas de desenvolvimento, são engendradas pelo e no trabalho. Pode-se afirmar que o homem cria o trabalho e o trabalho recria o homem.

A atividade fundamental da humanidade, o trabalho, faz a espécie dar um salto qualitativo rumo ao desenvolvimento infinito de suas potencialidades, capacidades e habilidades e isso pode ser notado quando vemos outros animais que, mediante seus dotes biológicos, superam o homem fisicamente, mas continuam num mundo preso ao ambiente natural e às suas forças e capacidades naturais; o homem, ao contrário dos animais, mesmo não tendo os dotes naturais para voar como os pássaros, transformou a natureza e construiu os aviões para poder voar como os pássaros e avançar à sua condição natural e biológica. 
Para ilustrarmos um pouco mais essa ideia vamos comparar um animal, o Leopardo, por exemplo, ao homem. Esse animal tem uma velocidade que qualquer homem nunca possuiu, ou seja, é superior ao homem nesse quesito, mas, o homem, por meio de sua atividade intencional diante da natureza, criou os meios para satisfazer sua necessidade de se locomover mais rápido que o Leopardo e construiu as rodas, os motores e supriu suas "falhas" ou limitações biológicas. Hoje, o Leopardo, que nasceu mais rápido que os homens, jamais consegue atingir as velocidades que os objetos culturais humanos conseguem, desde um carro até um avião, ou um foguete.

Cada geração começa, a sua vida num mundo de objetos e de fenômenos criados pelas gerações precedentes. Ela apropria-se das riquezas deste mundo participando no trabalho, na produção e nas diversas formas de atividade social e desenvolvendo assim aptidões especificamente humanas que se cristalizam, encarnaram nesse mundo. (LEONTIEV, 2004).

Todo o processo de evolução e desenvolvimento em que o homem se tornou humanizado, o qual ainda continua em intenso movimento, deve ser reconhecido a partir da ação desse homem, pois sem o trabalho, esse homem permaneceria na sua condição mais primitiva, na sua condição de mera espécie e não conquistaria a sua liberdade.

O processo em que o homem se tornou homem se deu em torno do trabalho, pois com e a partir do trabalho, o homem, sempre ativo dentro de um contexto de relações sociais, possibilitou o desenvolvimento dos processos fundamentais que caracterizaram a sua humanidade, dentre eles, a linguagem. Ou seja, como aptidão legítima do homem, e no âmbito do processo histórico de desenvolvimento humano, com e a partir do trabalho, a filogênese da linguagem tem seu desenvolvimento.

A produção da linguagem como da consciência e do pensamento, está diretamente misturada na origem, à atividade produtiva, á comunicação material dos homens.

$\mathrm{O}$ elo direto que existe entre palavra e a linguagem, de um lado, e a atividade de trabalho dos homens, e do outro é a condição primordial sob a influência da qual eles se desenvolveram enquanto portadores do reflexo consciente e "objetivado" da realidade. Significando no processo de trabalho, um objeto, a palavra distingue-o e generaliza-o para consciência individual, precisamente na sua relação objetiva e social, isto é como objeto social. (LEONTIEV, 2004, p.93). 


\section{O desenvolvimento da ontogênese da linguagem}

Neste tópico, buscamos contemplar aspectos referentes à ontogênese da linguagem, ou seja, ao processo de apropriação, pelo homem, da linguagem, construção fundamentalmente histórico-humana. Para tanto, iniciamos abordando aspectos da palavra, a mais simples e menor parte da linguagem, porém a estrutura fundamental para a sua explicação.

A palavra, como base estrutural da linguagem, possui duas funções fundamentais: a primeira função é o chamado sistema categorial ou significado, o qual tem como essência a separação de determinados traços dos objetos em gêneros e categorias; a segunda função ou referência objetal consiste em indicar o objeto em si, como, por exemplo, as suas ações em dada situação do chamado mundo real.

Nesse viés, Luria (1986) entende a palavra como cumpridora de um enorme trabalho realizado na historia social da linguagem.

Partindo dessas premissas, a teoria histórico-cultural deu um grande salto qualitativo no entendimento da linguagem, com os estudos de Vigotsky (apud LURIA, 1986), em que se buscou demonstrar que tanto a referencia objetal quanto o significado da palavra estão no desenvolvimento da ontogênese em constante mutação. Essa constante mutação da linguagem ao longo do desenvolvimento infantil confere um novo rumo ao entendimento dos processos psíquicos humanos.

Por desenvolvimento semântico da palavra, L. S. Vigotski entendia que, no processo de desenvolvimento da criança tanto a referência da palavra ao objeto como a separação de suas correspondentes características, a codificação dos traços dados e a inclusão do objeto num determinado sistema categorial não permanecem imutáveis, mudam à medida que a criança se desenvolve.

Por desenvolvimento sistêmico da palavra entendia que por trás do significado nas diferentes etapas do desenvolvimento, encontram-se diferentes processos psíquicos; sendo assim, com o desenvolvimento da palavra, muda não só a sua estrutura semântica, mas também sua estrutura psicológica. (LURIA, 1986, p. 44).

Nessa perspectiva a psicologia soviética entende a linguagem e, consequentemente, suas relações e enlaces com os processos psíquicos superiores, mediante o viés do materialismo histórico-dialético, o que muda totalmente a concepção de desenvolvimento da psique humana, livre do idealismo ou do entendimento mecânico desses processos marcantes em outras vertentes teóricas. 
Segundo a Teoria Histórico-Cultural, o sentido de uma palavra é aquele que o individuo toma para si, considerando o seu "tempo" e "lugar" histórico. Por exemplo, a palavra livro, pode assumir significados diferentes para um estudante universitário e para um funcionário de uma editora que produz esse livro.

Assim, por significado é possível entender a construção histórica da palavra, por meio da qual, além de assinalar o objeto em si, assinala, confere, nomeia todas as propriedades, relações e ações de dado objeto, exemplificado: a palavra casa que tem o seu significado social construído, como o lugar designado para abrigar pessoas, sendo possível ser construída com vários tipos de materiais (tijolos, madeiras, pedras, etc.). Segundo o próprio Luria (1986), o significado é um sistema estável de generalizações, que se pode encontrar em cada palavra igualmente para todas as pessoas.

Vemos então, que a mesma palavra possui um significado, formado objetivamente ao longo da historia e que, em forma potencial, conserva-se para todas as pessoas refletindo as coisas com diferentes profundidade e amplitude. Porém junto com o significado, cada palavra tem um sentido que entendemos como a separação, neste significado, daqueles aspectos ligados à situação dada e com as vivências afetivas do sujeito. (LURIA, 1986).

Diante dessa análise, é possível entendermos o significado como o elemento primordial da linguagem, sendo o sentido o fundamento estrutural da comunicação por meio do qual o sujeito materializa sua percepção e nesse processo concretiza a vida da linguagem humana.

Partindo do pressuposto de que a linguagem só foi concretizada ao longo da história, na e pela atividade humana, como entende os pesquisadores da Teoria Histórico-Cultural, temos que, na criança, esse processo de apropriação de inicio tem um caráter simpraxico, estando sempre ligado a prática das situações. Como é sabido, tal processo, na ontogênese da linguagem, não ocorre como na filogênese, pois na filogênese esse processo se deu na atividade fundamental do homem (o trabalho); no e pelo trabalho humano surgiu a necessidade da comunicação e dessa necessidade surgiu a linguagem.

Apesar das duas formas terem um caráter simpraxico, ou seja, estarem, de início, relacionadas à prática, com o seu desenvolvimento há uma separação e, com isso, surge a possibilidade da abstração por meio de um sistema de códigos. A filogênese tem o seu desenvolvimento baseado no trabalho humano, o que na ontogênese não é possível, pois o indivíduo ainda não estaria preparado para tal. 
A ontogênese da linguagem ocorre na apropriação dos conhecimentos adquiridos na historia humana, através da relação entre crianças e adultos, ou seja, a linguagem na ontogênese está ligada sempre as relações sociais que as crianças estabelecem com os adultos.

É evidente que todas estas características psicofisiológicas são formadas pela língua que o homem fala e não inatas, ao ponto do conhecimento das características de uma língua dada permitir descrever outras, com a maior verossimilhança, sem qualquer estudo particular. A principal característica do processo de apropriação ou de "aquisição" que descrevemos é, portanto, criar no homem aptidões novas, funções psíquicas novas. É nisto que se diferencia do processo de aprendizagem dos animais. Enquanto este último é resultado de uma adaptação individual do comportamento genérico, a condições de existências complexas e mutantes, assimilação no homem é um processo de reprodução, nas propriedades do indivíduo, das propriedades e aptidões historicamente formadas na espécie humana. (LEONTIEV, 2004).

Partindo da citação acima, de Leontiev (2004), podemos afirmar que a linguagem não pode ser considerada como um processo inato e sim apropriado socialmente pelo indivíduo na relação com o outro. Segundo Luria (1986, p.30):

$O$ inicio da verdadeira linguagem da criança e a apropriação da primeira palavra, que é o elemento desta linguagem, está sempre ligado à ação da criança é a sua comunicação com os adultos. As primeiras palavras da criança, diferente de seus primeiros sons não expressam seus estados, mas sim estão dirigidas ao objeto e o designam, no entanto, essas palavras possuem no início um caráter simpraxico, estão fortemente enlaçadas com a prática.

Em um segundo momento, a palavra começa a separar-se da ação prática, o vocabulário amplia-se. Essa ampliação é causada pelo fato de o motivo das palavras não darem mais conta das relações e enlaces com o grande número de objetos apropriados.

\section{Considerações finais}

Com este artigo, não tivemos a pretensão, absolutamente, de apresentar aspectos que não são conhecidos dos estudiosos da Teoria Histórico-Cultural e, nem tampouco, esgotar as discussões sobre os aspectos aqui abordados. Acreditamos que nossa contribuição se situa, como explicitado, em apresentar, maneira didática, aspectos dos processos de desenvolvimento e da apropriação da linguagem pelo homem, como nos 
foi possível apropriar no âmbito das nossas discussões e estudos realizados em cursos de formação de professores e em grupos de pesquisas que centram suas discussões em aspectos segundo a perspectiva da Teoria Histórico-Cultural, ou escola de Vygotsky e seus seguidores.

Segundo Neves e Damiani (2006, p.7), “os teóricos vinculados a essa corrente de pensamento preocupavam-se sempre em caracterizá-la naquilo em que ela se diferenciava das demais, ou seja, sua abordagem histórico-social do psiquismo humano."

Muitos autores denominaram a teoria de Vygotsky como socioconstrutivista ou sociointeracionista, pois reuniram em uma concepção epistemológica autores como Paulo Freire, Wallon, Vygotsky, Luria, Piaget entre outros (DUARTE, 1999 apud NEVES; DAMIANI, 2006, p.7), sendo que Piaget é autor de uma teoria bastante difundida nos dias atuais, que muitos conhecem como construtivismo.

Segundo Palangana (1994, p.79-80):

É sabido que Vygotsky e Piaget, coincidentemente, nasceram no mesmo ano e, ainda, que suas obras foram iniciadas mais ou menos na mesma época. Assim sendo, o cenário em psicologia com o qual Vygotsky se depara não é diferente da situação enfrentada por Piaget. Entretanto, é importante ressaltar que estas afirmações não significam em absoluto, tentativas para minimizar as divergências expressivas entre o contexto político-sociais em que cada um viveu a partir dos quais construíram suas teorias.

Finalmente, ressalta-se que entendemos a Teoria Histórico-Cultural como a única que considera o homem como um todo, não ignorando o seu desenvolvimento biológico, porém considerando centralmente as relações sociais e a sua importância tanto no desenvolvimento da linguagem quanto no desenvolvimento global do homem, além de considerar o desenvolvimento e a apropriação da linguagem como o ponto central do desenvolvimento humano. Daí, termos como nosso referencial a Teoria Histórico-Cultural.

THE DEVELOPMENT OF THE PHYLOGENESIS AND OF THE LANGUAGE'S ONTOGENESIS: SOME ASPECTS, ACCORDING OF THE HISTORICALCULTURAL THEORY 
ABSTRACT: Are presented in this article, the results of the studies focused on analysis and interpretation of the developmental aspects of the phylogeny and ontogeny of language. These studies took place in teacher training courses and research groups that focus their discussions in aspects from the perspective of cultural-historical theory or school of Vygotsky and his followers. In this sense, all text is guided according formulation of the who development and appropriation of the language is a culturalhistorical processes resulting from the human need for communication and have originates in the vital human activity, in the work socially constituted. At the end, we emphasize, centrally, social relations and their importance in language development and global development, addition to considering the development and appropriation of language as the central point to human development. For the studies were used bibliografy research procedures, basically, reading, analysis, and, albeit brief, interpretation in the light of research literature.

KEYWORDS: Education. Teaching formation. Language's Phylogenesis. Language's Ontogenesis. Historical-Cultural Theory.

\section{REFERÊNCIAS}

LEONTIEV, A. N. O desenvolvimento do psiquismo. 2.ed. São Paulo: Centauro, 2004.

LESSA, S; TONET, I. Introdução à filosofia de Marx. São Paulo: Expressão Popular, 2008.

LURIA, A. R. Pensamento e linguagem. As ultimas conferencias de Luria. Porto Alegre: Artes Medicas, 1986.

NEVES, R. A; DAMIANI, M. F. Vygotsky e as teorias da aprendizagem. São Leopoldo. UNIrevista.v.1, n.2, p.1-10, abr. 2006. Disponível em:

<http://www.miniweb.com.br/educadores/Artigos/PDF/vygotsky.pdf>. Acesso em: 17 fev. 2015.

PALANGANA, I. C. Desenvolvimento e aprendizagem em Piaget e Vygotsky: a construção do social. São Paulo: Plexus, 1994.

VYGOTSKY, L. S. Pensamento e linguagem. São Paulo: Martins Fontes, 1993. 